Original Research Article

\title{
Soft tissue coverage techniques for management of open fractures of tibia (type IIIB)
}

\author{
Mahaveer Meena, Vikas Chavan*, Sanjay Kumar Ghilley, Nilesh Kumar Jangir
}

Department of Orthopaedics, Jhalawar Medical College, Jhalawar, Rajasthan, India

Received: 17 March 2020

Revised: 12 April 2020

Accepted: 14 April 2020

*Correspondence:

Dr. Vikas Chavan,

E-mail: chavanvikas88@yahoo.com

Copyright: (c) the author(s), publisher and licensee Medip Academy. This is an open-access article distributed under the terms of the Creative Commons Attribution Non-Commercial License, which permits unrestricted non-commercial use, distribution, and reproduction in any medium, provided the original work is properly cited.

\begin{abstract}
Background: Open fractures are surgical emergencies; incidence of open fractures is increasing with more high-energy road traffic accidents. The tibia is exposed to frequent injury because of its location. The need for aggressive debridement, adequate fracture fixation, and early flap coverage in reducing the morbidity cannot be over emphasized. Methods: Treatment of open fracture by immediate debridement and anatomical fracture reduction using external fixator device. Gastrocnemius muscle flap done in upper 1/3 open fractures (type IIIB) with larger defects along with split thickness skin graft (STSG). In middle and lower 1/3 open fractures (type IIIB), fasciocutaneous and soleus muscle flaps done with relatively smaller soft tissue defects and exposed bone with STSG.

Results: The study included 15 patients with open tibia fracture Gustillo Anderson type IIIB classified after the initial debridement. Excellent flap takes up was seen in all cases. 11 cases (73.3\%) achieved union at the end of 6 months follow-up while 4 cases $(26.7 \%$ ) showed delayed union which required additional procedures like BMI or bone graft. Conclusions: Soft tissue coverage techniques like fascicutaneous flap, gastrocnemius and soleus muscle flap had a definitive role in the management of open fractures of tibia (type IIIB).
\end{abstract}

Keywords: Open fracture, Tibia, Flap, Skin graft

\section{INTRODUCTION}

An open fracture means communication between the external environment and the fracture. Four components characterize the injury: fracture, soft-tissue damage, neurovascular compromise, contamination. ${ }^{1-2}$ The Gustilo and Anderson classification is used most commonly to classify open fractures.

Open fractures are surgical emergencies, incidence of open fractures is increasing with more high-energy road traffic accidents. The tibia is exposed to frequent injury because of its location; it is the most commonly fractured long bone. Because one third of the tibial surface is subcutaneous throughout most of its length, open fractures are more common in the tibia than in any other major long bone. The blood supply to the tibia is more precarious than that of bones enclosed by heavy muscles elsewhere. ${ }^{3}$

Gustillo and Anderson Type type III open fracture tibia has been a major challenge for the entire team of trauma surgeons involved in the treatment. The need for aggressive debridement, adequate fracture fixation, and early flap coverage in reducing the morbidity cannot be over emphasized. ${ }^{4}$

Provision of an intact healthy soft-tissue envelope around fracture is beneficial for bone healing to occur and function to be restored. ${ }^{5}$ Soft-tissue coverage of severe type III open fractures of leg diminishes the rate of infection, nonunion, and secondary amputation when it is performed early and expedites the bone healing process. ${ }^{6}$ 
Various options for reconstruction of soft-tissue defect in open fractures, split skin graft (SSG), fasciocutaneous flap, rotational muscle flap (with SSG), and free muscle flap (with SSG). ${ }^{7}$

As these procedures are collective osteoplastic approach. The flaps used to cover the soft tissue defects in open fracture of the tibia, could be non-microvascular, which are technically less demanding or microvascular, involving steep learning curve and available only in few centers in a developing country like ours.

An orthopaedic surgeon equipped with theoretical and practical knowledge of the local vascular anatomy required to harvest an appropriate local or a regional flap to cover exposed bone or metal in open fractures of tibia. Since there is lack of plastic surgeon in our institute, we perform these procedures with relatively simpler cases which doesn't require microvascular flaps and by decreasing the burden of higher centers.

\section{METHODS}

The study was conducted on 15 patients of open fracture of the tibia admitted in Jhalawar Medical College, Jhalawar, Rajasthan, India between March 2018 to 2019.

Patients with open fracture were initially resuscitated in emergency department following advanced trauma life support guidelines. Treatment of open fracture by immediate debridement and anatomical fracture reduction using external fixator device. Soft tissue injury and any bone loss was assessed using 'Gustillo Anderson classification' and wound was classified after debridement. Regular inspection and dressing of the wound, if needed re-debridement was done until healthy granulation tissue is obtained.

Pre-operative planning for the soft tissue defect with exposed bone was done once the patient's general condition improved, healthy granulation tissue of the wound and negative pus culture and sensitivity. The leg defect was divided into upper $1 / 3$, middle $1 / 3$ and lower $1 / 3$.

In our study, gastrocnemius muscle flap done in upper $1 / 3$ open fractures (type IIIB) with larger defects along with split thickness skin graft (STSG). In middle and lower 1/3 open fractures (type IIIB), fasciocutaneous and soleus muscle flaps done with relatively smaller soft tissue defects and exposed bone with STSG.

Post-operatively, all patients received 5 days of antibiotics, then changed to oral antibiotics. Graft inspection done on $5^{\text {th }}$ day in all patients. Care taken to prevent any seroma or haemotoma formation. Once the flap was taken up well patient was discharged.

Regular follow up done once in 2 weeks for initial 1 month and monthly visit for next 3-4 months for inspection of flap and clinico-radiological assessment of fracture union. External fixation was removed once union was established, plaster of paris cast was applied for 4-6 weeks and allowed to weight bear after bony union. Follow up was done for a minimum period of 5-6 months.

It was difficult to analyze the data with standard statistical tools since the data obtained was not homogenous in terms of type and number of soft tissue reconstruction, type of fracture fixation, location of fracture, extent of bony comminution and extent of soft tissue disruption. Hence, clinical outcomes were analyzed using percentages and averages.

\section{RESULTS}

The study included 15 patients with open tibia fracture Gustillo Anderson type IIIB classified after the initial debridement. In all the cases initial debridement and fracture stabilization done with external fixation device.

Out of 15 patients, 13 were males $(86.7 \%)$ and 2 females (13.3\%), with age group ranging from 20-60 years (Figure 1). $80 \%$ of the patients sustained injury by road traffic accident, while $13.3 \%$ and $6.7 \%$ injury due to fall from height and wall collapse respectively (Table 1). 9 cases $(60 \%)$ had communited fracture and remaining 6 cases (40\%) had either transverse or oblique fracture (Table 2).

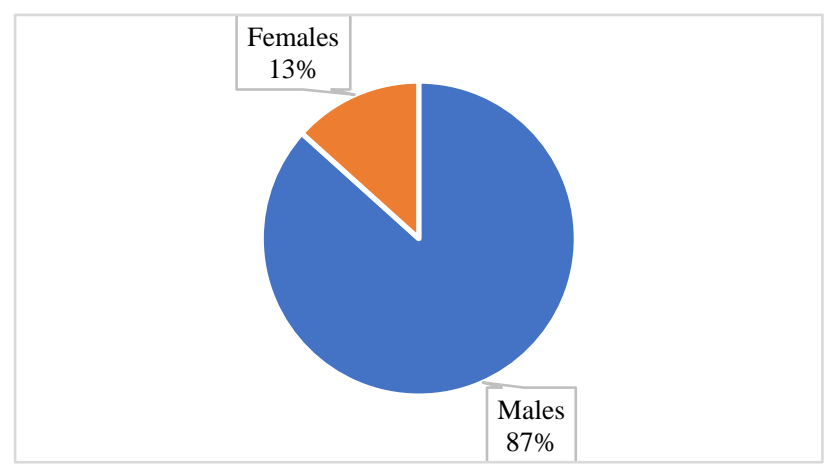

Figure 1: Sex distribution.

Table 1: Mode of injury.

\begin{tabular}{|lll|}
\hline Mode of Injury & Cases & Percentage (\%) \\
\hline Road traffic accidents & 12 & 80 \\
\hline Fall from height & 02 & 13.3 \\
\hline Wall collapse & 01 & 6.7 \\
\hline $\begin{array}{l}\text { Total number of } \\
\text { patients }\end{array}$ & 15 & 100 \\
\hline
\end{tabular}

Table 2: Type of fracture.

\begin{tabular}{|lll|}
\hline Type of fracture & Cases & Percentage (\%) \\
\hline Communited fracture & 09 & 60 \\
\hline $\begin{array}{l}\text { Transverse/oblique } \\
\text { fracture }\end{array}$ & 06 & 40 \\
\hline Total number of patients & 15 & 100 \\
\hline
\end{tabular}


In our study, fasciocutaneous flap done in 8 cases $(53.3 \%)$, gastrocnemius muscle flap in 4 cases $(26.7 \%)$ and soleus muscle flap in 3 cases $(20 \%)$ performed for open tibia fractures. In all 4 cases of gastrocnemius muscle flap, medial head of gastrocnemius was used (Figure 2). All the cases required split thickness skin graft (STSG) which was harvested from ipsilateral or contralateral thigh.

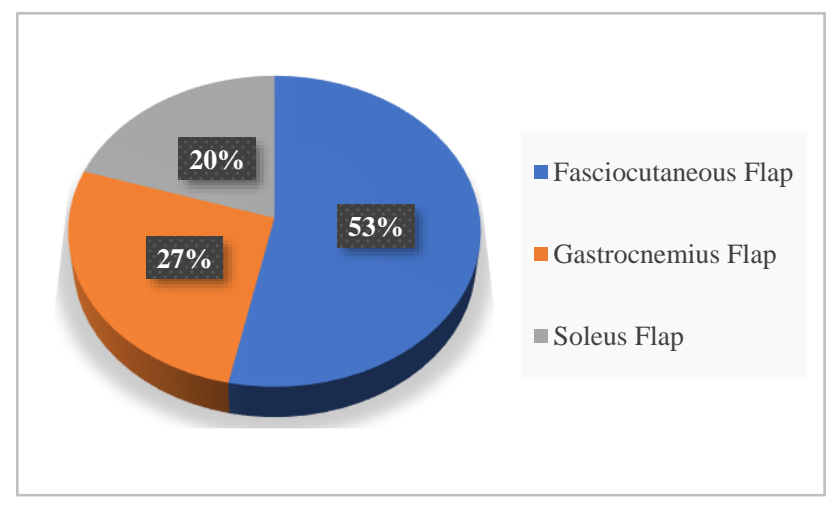

Figure 2: Types of flap.

Average duration of follow-up was 20 weeks (range 16-24 weeks). Excellent flap takes up was seen in all cases. 1 case $(6.7 \%)$ developed infection and 1 case $(6.7 \%)$ had STSG necrosis which was further managed accordingly (Figure $3) .11$ cases $(73.3 \%)$ achieved union at the end of 6 months follow-up while 4 cases $(26.7 \%)$ showed delayed union which required additional procedures like BMI or bone graft.

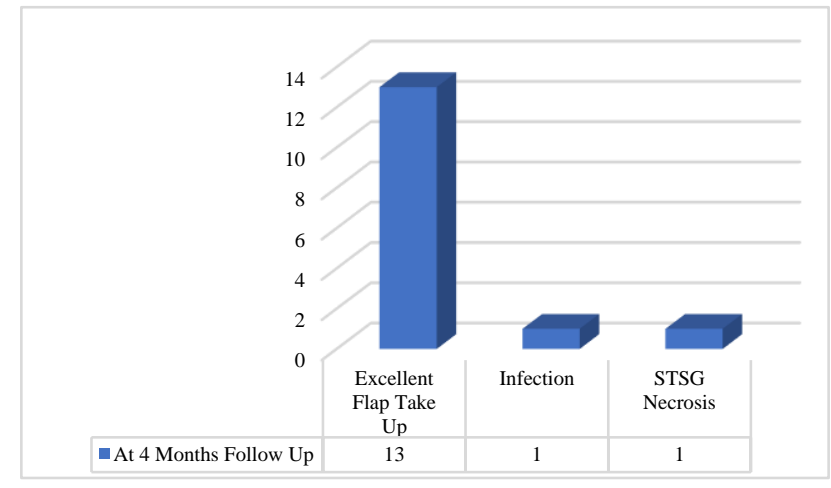

Figure 3: At 4 months follow up.

There were no case of complete or partial flap loss. No functional deficit of donor site was noticed in any of the cases. Except one case, all patients had an aesthetically acceptable appearance with complete coverage of the defect.

\section{DISCUSSION}

Early and precise management may improve overall outcome both aesthetically and functionally of the patients with soft tissue defect after open fracture of tibia.
Our study was conducted on patients with open tibia fracture type IIIB classified after initial debridement with the aim of proper management and improving the outcome by various soft tissue reconstruction techniques like gastrocnemius muscle flap, soleus muscle flap and fasciocutaneous flap. Prospective study of 15 patients were carried out during the period of March 2018 to 2019. Patients were followed clinically for a minimum period of 5-6 months.

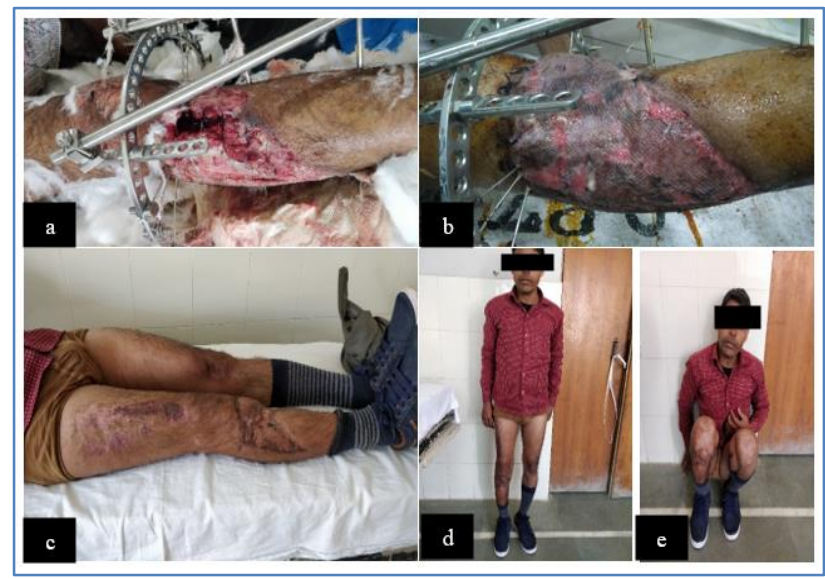

Figure 4: (a) Preoperatively, (b) postoperative dressing at 7th day, (c, d, e) at 4 months follow up. Patient 1: a 35 years old male patient came with compound proximal tibia fracture (type IIIB) right side, initially managed with debridement and hybrid external fixator. Regular dressing was done to obtain healthy granulation tissue. Gastrocnemius flap with skin graft was done after 20 days.

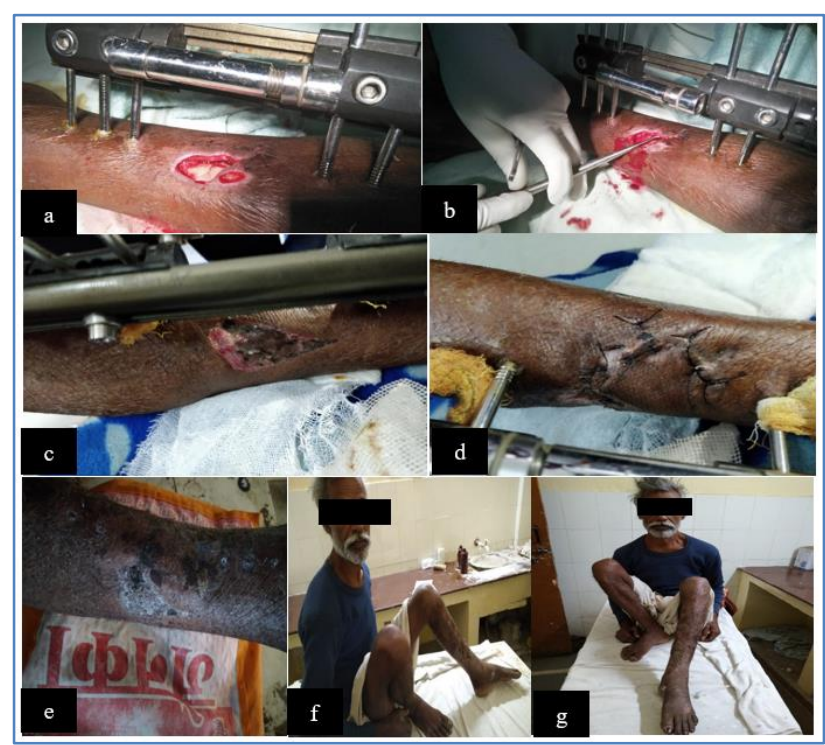

Figure 5: (a, b) Preoperatively, (c) at 1 month follow up - donor site, (d) at 1 month follow up - recipient site, $(e, f, g)$ at 3 months follow up.

Patient 2: a 50 years old male came with compound tibia fracture mid shaft (type IIIB) left side, initially debridement and LRS external fixator was done. After achieving healthy granulation tissue, a fasciocutaneous flap was done along with skin grafting over donor site. 
In our study, $53.3 \%$ of fasciocutaneous flap, $26.7 \%$ of gastrocnemius muscle flap and $20 \%$ of soleus muscle flap were done with no evidence of complete or partial flap loss. In a study by Fischer free muscle flap was done in $50 \%$ of cases while local muscle flap was done in $50 \%$ of cases. ${ }^{8}$ Flap failure rate was $17 \%$. In another study by Cole fasciocutaneous flap was done in all patients, out of which $4 \%$ had flap failure. ${ }^{9}$ In a study of Chung et al. gastrocnemius flap loss is seen, which they had attributed to inadequate tunneling of flap. ${ }^{10}$

In a study series conducted by Wiss et al noted 3\% deep infection and $33 \%$ nonunion. ${ }^{11}$ Complications in our study, development of deep infection and split thickness skin graft necrosis was seen in $6.7 \%$ each while $26.7 \%$ had delayed union.

\section{CONCLUSION}

Soft tissue coverage techniques like fascicutaneous flap, gastrocnemius and soleus muscle flap had a definitive role in the management of open fractures of tibia (Type IIIB). The goals of soft tissue reconstruction were to obtain a safe and durable coverage, to avoid infection and to expedite the fracture union.

\section{ACKNOWLEDGEMENTS}

As we complete this humble contribution to scientific pursuit, it gives me immense pleasure to acknowledge the guidance provided by my distinguished mentors. With proud privilege and deep sense of respect I like to express my gratitude and indebtedness to Dr. Purushottam Jhanwar, professor and H.O.D (department of orthopaedics) for their constant inspiration, extensive encouragement and support. I express my sincere gratitude to Dr. Mahaveer Meena, Dr. Sanjay Kumar Ghilley and Dr. Nilesh Kumar Jangir for their valuable contribution, suggestion during my study.

\section{Funding: No funding sources}

Conflict of interest: None declared

Ethical approval: The study was approved by the institutional ethics committee

\section{REFERENCES}

1. Norris BL, Kellam JF. Soft-Tissue Injuries Associated with High-Energy Extremity Trauma: Principles of Management. J Am Acad Orthop Surg. 1997;5(1):37-46.

2. Templeman DC, Gulli B, Tsukayama DT, Gustilo RB. Update on the management of open fractures of the tibial shaft. Clin Orthop Relat Res. 1998;350:1825.

3. George W. General principles of fracture treatment. In: Terry Canale S, Beaty JH, editors. Campbell's Operative Orthopaedics. 11th ed. Philadelphia: Elsevier; 2007: 3025.

4. Small JO, Mollan RA. Management of soft tissue in open tibia fractures. Br J Plast Surg. 1992;45:571-7.

5. Chittoria R, Mishra SM. Fasciocutaneous flaps in reconstruction of lower extremity: Our experience. Kathmandu Univ Med J (KUMJ). 2004;2:344-8.

6. Mackenzie DJ, Seyfer AE. Reconstructive surgery lower extremity coverage. In: Mathes SJ, Hentz VR, editors. Plastic Surgery Trunk and Lower Extremity. 2nd ed. Philadelphia: Saunders Elsevier; 2006: 1364.

7. Mess D. Lower extremity trauma principles of evaluation and early management. In: Cohen $\mathbf{M}$, editor. Mastery of Plastic and Reconstructive Surgery. 1st ed. New York: Little Brown and company; 1994: 1773.

8. Fischer MD, Gustilo RB, Verecka TF. The timing of flap coverage, bone grafting and IM nailing in patients with tibial shaft fractures with extensive soft tissue injury. J Bone Joint Surg Am. 1991;73(9):1316-22.

9. Cole JD, Ansel LJ, Schwartzberg R. A sequential Protocol for Management of severe open tibial fractures. Clin Orthop. 1995;315:84-103.

10. Chung, Jae Y, Kim, Gene, Sohn, Kyu B. Reconstruction of a lower extremity soft-tissue defect using the gastrocnemius musculoadipofascial flap. Ann Plast Surg. 2002;49:91-5.

11. Wiss DA, Sherman R, Oechsel M. External skeletal fixation and rectus abdominis free flap in the management of severe open fractures of the Tibia. Orthop Clin North Am. 1993;24(3):549-56.

Cite this article as: Meena M, Chavan V, Ghilley SK, Jangir NK. Soft tissue coverage techniques for management of open fractures of tibia (type IIIB). Int J Res Orthop 2020;6:773-6. 